\title{
VIBRATIONS IN BUILDINGS DUE TO RAILWAY TRAFFIC IN TUNNELS: MODELLING STRATEGIES AND INFLUENCE OF SOIL STIFFNESS
}

\author{
P. Lopes ${ }^{1}$, P. Alves Costa ${ }^{2}$, R. Calçada ${ }^{3}$ and A. Cardoso ${ }^{4}$ \\ ${ }^{1}$ Department of Civil Engineering, Faculty of Engineering of University of Porto \\ e-mail: cpl@isep.ipp.pt \\ ${ }^{2}$ Department of Civil Engineering, Faculty of Engineering of University of Porto \\ pacosta@fe.up.pt \\ ${ }^{3}$ Department of Civil Engineering, Faculty of Engineering of University of Porto \\ ruiabc@fe.up.pt \\ ${ }^{4}$ Department of Civil Engineering, Faculty of Engineering of University of Porto \\ scardoso@fe.up.pt
}

Keywords: Railway vibrations in tunnels, Soil-structure interaction, 2.5D FEM-PML

\begin{abstract}
In this paper a numerical study about the influence of soil stiffness on the assessment of vibrations induced by railway traffic in tunnels is performed. A comprehensive numerical model is used to achieve the lumped objective, where the source of vibration (traintrack interaction), the propagation of vibrations (tunnel-ground system) and their reception (building close to the railway infrastructure) are simulated by a sub-structuring approach. It was found that the soil stiffness plays a relevant role on the mechanisms of propagation of vibrations through the ground as well as on the soil-structure interaction. Regarding the last topic, different approaches were attended for the inclusion of the SSI effects, namely a detailed boundary elements formulation and a simplified lumped-parameter model. The study performed revealed that the usage of lumped parameter models can be faced as a good option taking into account the compromise between accuracy of the solution and reduction of the computation effort.
\end{abstract}




\section{Introduction}

The relevance of environmental problems related with vibrations induced by underground railway traffic has increased over the last years. Actually, the influence of vibrations on working and living environments is now considered one of the seven main environmental problems of modern societies $[1,2]$. The first step to the minimization of the negative impact induced by vibrations due to railway traffic lies on a better understanding of this complex problem. Therefore, several prediction models have been developed during recent years, ranging from scope models [3] to analytical models $[4,5]$, without forgetting complex numerical models, as the ones suggested by Clouteau et al [6], Gupta et al. [7, 8] and Hung and Yang [9], among others.

Due to the inherent complexity of the problem, Lai et al [10] suggests that the development of a comprehensive prediction tool for railway-induced ground vibrations should consider three distinct perspectives: i) the source problem associated to train-track dynamic interaction; ii) the propagation problem, comprising the transmission of borne vibrations from the source to the receiver; iii) the structural response problem, regarding to the soil-structure dynamic interaction developed due to the vibration field that impinges buildings surrounding railway facilities.

The source problem has been object of intensive research during the last couple of years, so that it is now possible to state that the excitation source provided by the dynamic interaction mechanism plays the most relevant role in terms of vibrations induced in the ground due to railway traffic [11, 12]. This fact demands for the solving of a dynamic interaction problem where the unsprung mass of the train plays an important role.

However, it should be emphasised that the major research effort is visible on the second part of the problem, i.e., the propagation of vibrations from the tunnel through the surrounding ground. In the present paper, a numerical model based on the 2.5D FEM-PML (perfectly matched layers) concept is used to simulate the propagation of waves induced by railway traffic in tunnels. [13].

In spite of the considerable recent advances in this topic, there is still a lack of studies comprising the complete problem, i.e., from the source to the receiver. The last part of the problem, comprising the dynamic response of the receiver (building close to the tunnel), has only been considered in a very small number of studies [14-17].

The present paper aims to contribute to a better discernment of the comprehensive problem, taking into account not only the generation and propagation of vibrations induced by railway traffic in tunnels, but also its effect inside of buildings close to the tunnel. The soil-structure interaction is taken into account by a detailed formulation based on the sub-structuring approach.

Among several parameters that influence the dynamic response of the system, Gupta et al.[18] concluded that soil stiffness plays an important role on the vertical vibration levels predicted at the ground surface. However, when the presence of the building is taken into account, the stiffness of the ground is also expected to affect the soil-structure interaction mechanism. So, the present paper develops a parametric study in order to assess the influence of soil stiffness not only on the vibration propagation mechanism, but also on the soil-structure (building) mechanism. Regarding this aspect, alternative approaches for dealing with SSI are investigated.

Finally, the paper ends with a summary of the main conclusions of the developed study.

\section{Numerical approach}

\section{$2.1 \quad$ Generalities}

Fig. 1 shows the main parts of the proposed numerical model, as well as the main steps involved in the solution [19]. As can be seen, a substructuring approach is followed, being each part of the problem simulated through distinct suitable approaches. 


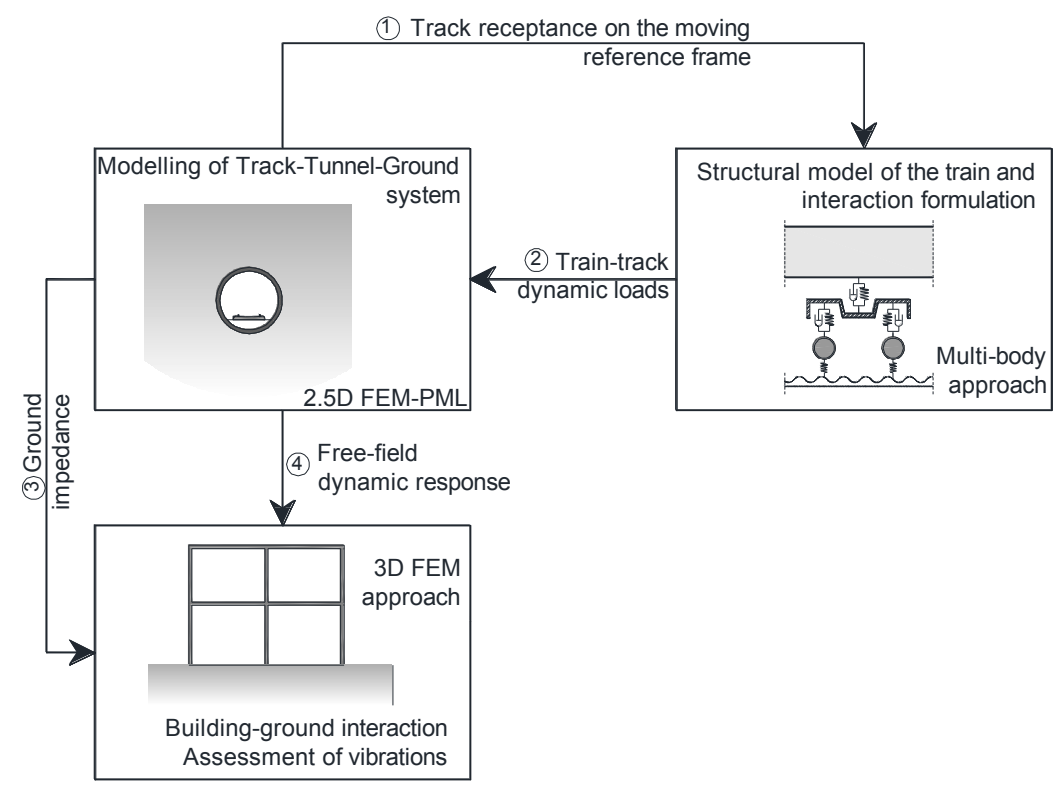

Fig. 1. Numerical modelling strategy.

Since the model depicted in Fig. 1 was previously presented and validated [20] by the authors, a detailed description of the models is omitted. The reader is advised to consult the following documents $[11,15,19,20]$ for a detailed description of the modelling strategy followed to simulate the source and the propagation medium.

Regarding the mathematical formulation followed for the soil-structure interaction, the reader can find a comprehensive description in recent papers of the same authors, namely on Lopes et al. [21]. Nevertheless, it should be referred that in the present paper two distinct methodologies are used for the assessment of the impedance of the building's footings: i) a 3D BEM approach; ii) a lumped parameter approach. Fig. 2 shows both approaches followed.

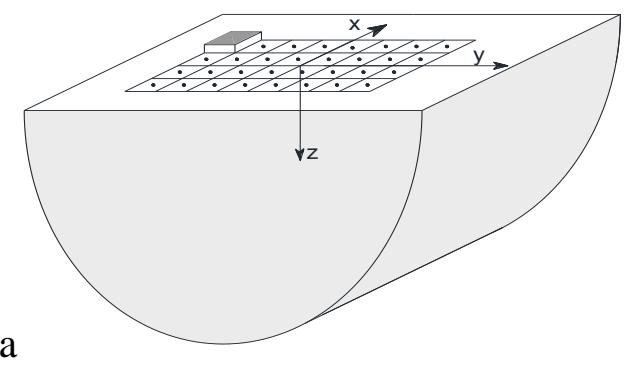

Fig. 2. Assessment of footing impedance: a) 3D BEM; b) lumped parameter model [21].

\section{Application example}

\section{1. $\quad$ Model Description}

Fig 3 represents a shallow tunnel embedded in a half-space. The circular geometry tunnel has a $6.0 \mathrm{~m}$ diameter and is lined on the inside with a thickness of concrete of $0.3 \mathrm{~m}$ (continuous liner, i.e., without joints along the longitudinal direction). The mechanical properties of the tunnel liner and the ground are also indicated in Fig 3. 


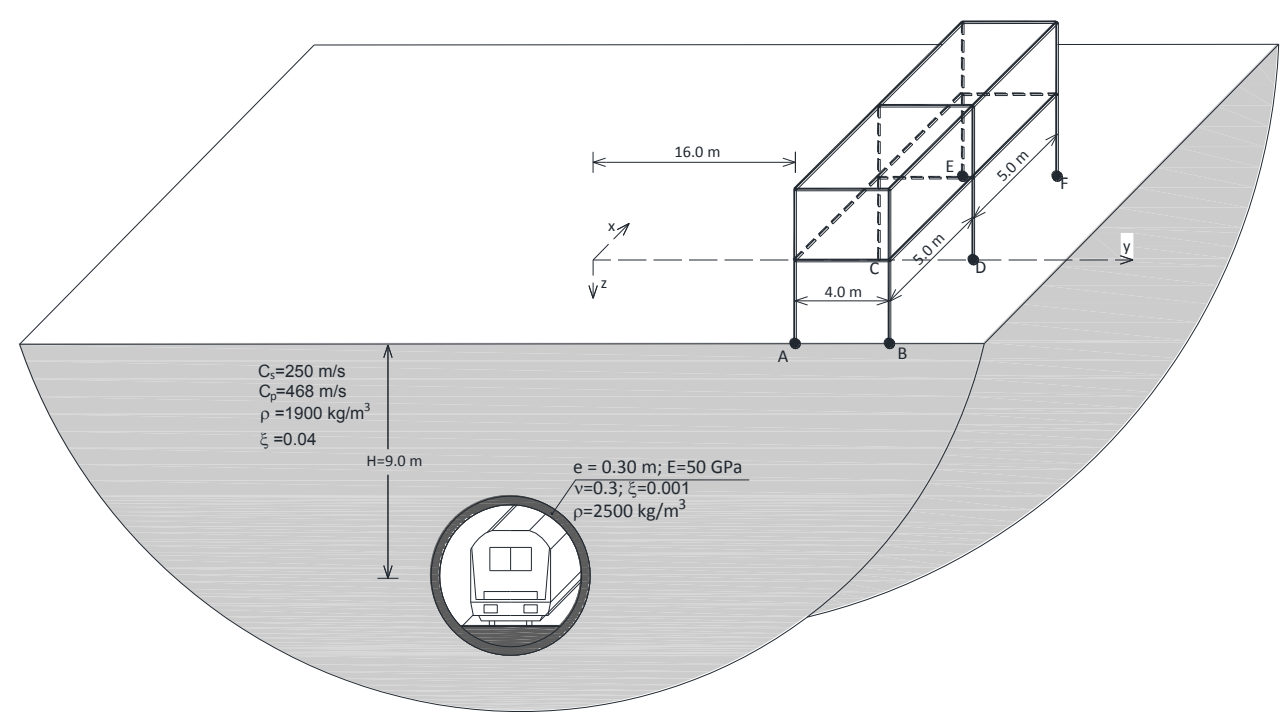

Fig 3. Geometry and properties of the application example.

The railway track is composed by a continuous concrete slab track $0.3 \mathrm{~m}$ thick and $2.5 \mathrm{~m}$ wide, with a longitudinal bending stiffness of $1.62 \times 108 \mathrm{~N} / \mathrm{m} 2$ and a mass of $2800 \mathrm{~kg}$ per unit of length. The rails, materialized by UIC60 profiles are continuously supported by railpads with a stiffness of $2.5 \times 108 \mathrm{~N} / \mathrm{m} 2$ and a damping coefficient of $6 \times 104 \mathrm{Ns} / \mathrm{m} 2$. It assumed a floating slab solution, introducing a resilient mat between the slab and the tunnel invert. The stiffness of the mat is $0.153 \times 109 \mathrm{~N} / \mathrm{m} 2$ per meter in the longitudinal direction and a damping of $5.5 \times 104 \mathrm{Ns} / \mathrm{m} 2$ is considered.

Regarding soil properties, three distinct scenarios are assumed according to

\section{Table 1:}

Table 1 - Properties of ground

\begin{tabular}{c|c|c|c|c}
\hline Scenario & Cs $(\mathrm{m} / \mathrm{s})$ & $v$ & $\rho\left(\mathrm{kg} / \mathrm{m}^{3}\right)$ & $\beta$ \\
\hline 1 & 150 & 0.3 & 1900 & 0.04 \\
\hline 2 & 250 & 0.3 & 1900 & 0.04 \\
\hline 3 & 410 & 0.3 & 1900 & 0.04 \\
\hline
\end{tabular}

Regarding the building, the presence of a two-story small building in the vicinity of the tunnel was also assumed. The geometry of the building is illustrated in Fig. 4. The footings of the building are squared with an area of $2 \times 2 \mathrm{~m} 2$. The most distant column alignment of the building is $20 \mathrm{~m}$ away from the plane of symmetry of the cross-section of the tunnel.

Table 2 summarizes the properties of the main elements of the building. Regarding the damping, Rayleigh damping factors were adopted in order to address a damping coefficient of around $2 \%$ in the frequency range between $5 \mathrm{~Hz}$ and $80 \mathrm{~Hz}$. The coordinates of the centre of the footing are: A($5 ; 16 ; 0) ; \mathrm{B}(-5 ; 20 ; 0) ; \mathrm{C}(0 ; 16 ; 0) ; \mathrm{D}(0 ; 20 ; 0) ; \mathrm{E}(5 ; 16 ; 0) ; \mathrm{F}(5 ; 20 ; 0)$.

Additionally, a distributed mass of $300 \mathrm{~kg} / \mathrm{m} 2$ was considered on the floors, in order to take into account the other permanent masses.

To compute the impedance of the ground, the area of the footing-ground interface was discretized by 144 square elements, corresponding to a maximum length size of $0.167 \mathrm{~m}$. In what concerns to the dimensions of the elements of the 2.5D FEM-PML model, it should be mentioned that the mesh was designed taking into account the recommendations presented by Yang et al.[22] and Alves Costa et al.[23].

Table 2 - Properties of the structural elements of the building

\begin{tabular}{c|c|c}
\hline Elements & Properties & Dimensions \\
\hline
\end{tabular}




\begin{tabular}{c|c|c}
\hline & $\mathrm{E}(\mathrm{GPa}), \nu, \rho\left(\mathrm{kg} / \mathrm{m}^{3}\right)$ & \\
\hline Slabs & $30,0.2,2500$ & Thickness: $0.25 \mathrm{~m}$ \\
\hline Beams & $30,0.2,2500$ & $0.3 \times 0.60 \mathrm{~m}^{2}$ \\
\hline Columns & $30,0.2,2500$ & $0.30 \times 0.30 \mathrm{~m}^{2}$ \\
\hline
\end{tabular}

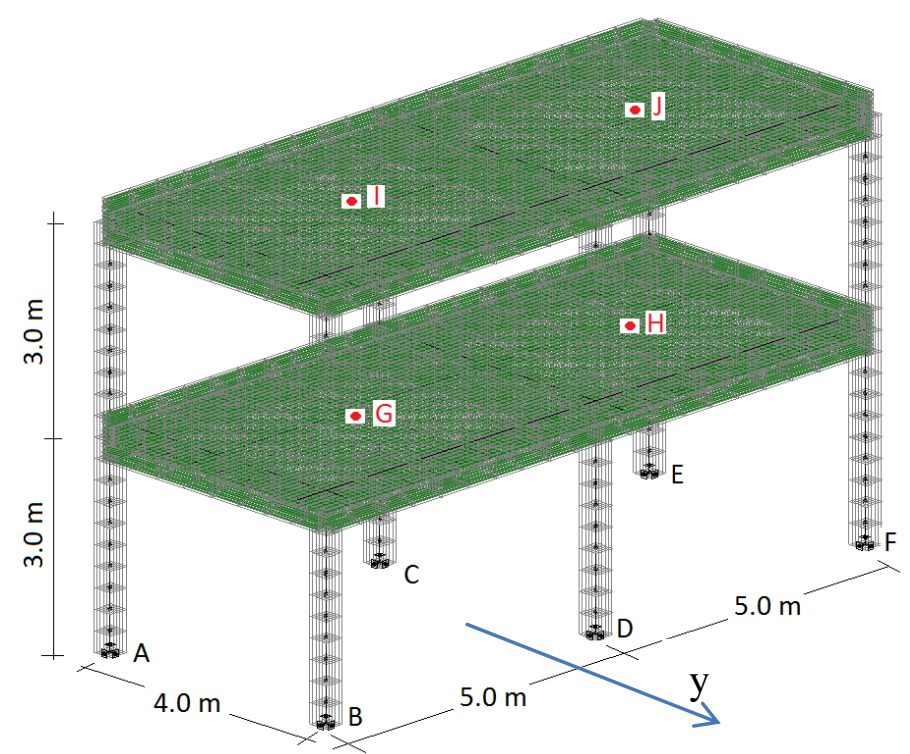

Fig. 4.Geometry of the building.

Regarding the rolling stock, the passage of the Alfa-Pendular train at a running speed of $40 \mathrm{~m} / \mathrm{s}$ was assumed. The main geometrical and mechanical properties of the Alfa-Pendular train are summarized in Fig. 5 and in Erro! A origem da referência não foi encontrada..

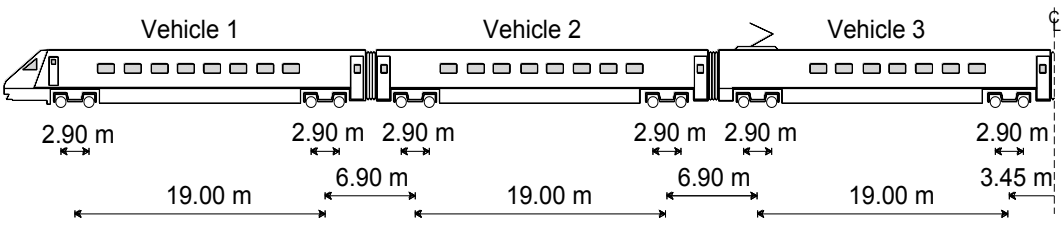

Fig. 5. Alfa-Pendular geometry.

Table 3 - Mechanical properties of the train

\begin{tabular}{c|l|l}
\hline Axles & $\mathrm{Mw}(\mathrm{kg})$ & $1538-1884$ \\
\hline $\begin{array}{c}\text { Primary sus- } \\
\text { pension }\end{array}$ & $\mathrm{Kp}(\mathrm{kN} / \mathrm{m})$ & 3420 \\
\hline \multirow{2}{*}{ Bogies } & $\mathrm{Cp}(\mathrm{kNs} / \mathrm{m})$ & 36 \\
\cline { 2 - 3 } & $\mathrm{Mb}(\mathrm{kg})$ & $4712-4932$ \\
\hline \multicolumn{2}{c|}{ Car body $\left(\mathrm{kg} / \mathrm{m}^{2}\right)$} & $5000-5150$ \\
\hline
\end{tabular}

As mentioned before, the train-track interaction is taken into account, so, the dynamic interaction mechanism is given by the unevenness of the track. An artificial unevenness profile was generated taking considering the power spectral density (PSD) of amplitude of the track unevenness for a range of wavelengths between $28 \mathrm{~m}$ and $0.55 \mathrm{~m}$. The following equation was used to address the PSD of the track unevenness [12]:

$$
\mathrm{S}\left(\mathrm{k}_{1}\right)=\mathrm{S}\left(\mathrm{k}_{1,0}\right)\left(\frac{\mathrm{k}_{1}}{\mathrm{k}_{1,0}}\right)^{-\mathrm{w}}
$$

where $\mathrm{k} 1,0=1 \mathrm{rad} / \mathrm{s}, \mathrm{w}=3.5$ and $\mathrm{S}(\mathrm{k} 1,0)$ is equal to $1 \mathrm{x} 10-8 \mathrm{~m} 3$.

Since the train speed was assumed to be $40 \mathrm{~m} / \mathrm{s}$, the adopted unevenness profile excites the train in the frequency range between $1.4 \mathrm{~Hz}$ and $72 \mathrm{~Hz}$. This range of frequencies is particularly interest- 
ing for the study of vibrations induced by traffic in buildings, since for frequencies above $80 \mathrm{~Hz}$ the building structure itself filters the vibration levels.

\subsection{Dynamic response of the track}

Fig. 6 shows the vertical velocity of the rail, at position $x=0 \mathrm{~m}$, during the passage of the train for the different scenarios under study (it is assumed that at $\mathrm{t}=0 \mathrm{~s}$, the last wheelset of the train is at $\mathrm{x}=0 \mathrm{~m}$ ). Since almost all the resilience of the track is given by the elastomeric elements (railpads and mats beneath the slab), the track displacements almost aren't affected by the elastic properties of the ground. However, it should be emphasize that outside the track, as for instance at the invert of the tunnel, the ground properties start to gain some relevance.

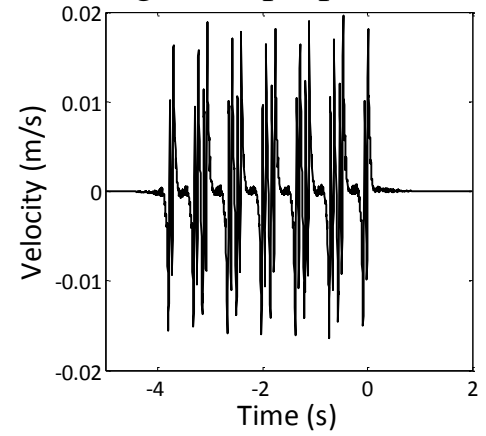

a

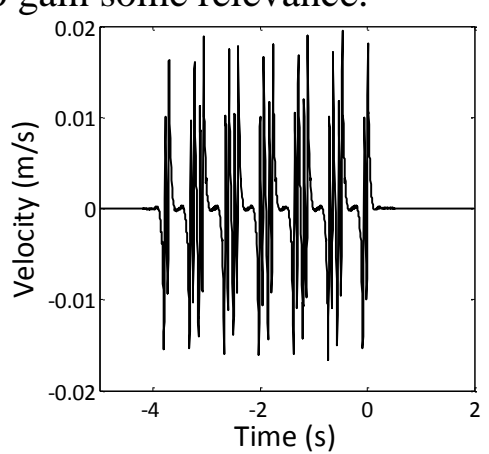

b

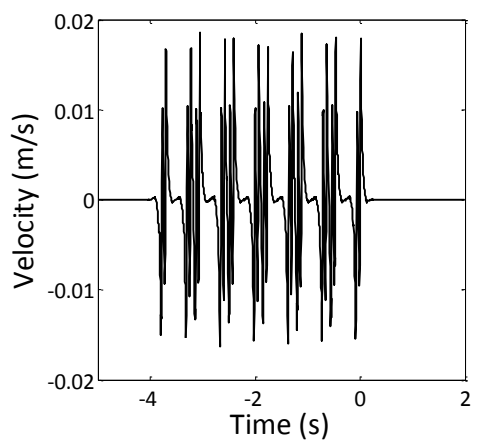

$\mathrm{c}$

Fig. 6. Time history of the vertical velocity of the rail for soil properties: a) $C s=150 \mathrm{~m} / \mathrm{s}$; b) $\mathrm{Cs}=250 \mathrm{~m} / \mathrm{s}$; c) $\mathrm{Cs}=410 \mathrm{~m} / \mathrm{s}$.

\subsection{The dynamic response of the building}

The SSI effects are considered by evaluating the footing impedance (or the dynamic stiffness), which can be done using one of the two methodologies previously mentioned. The first methodology, based on a 3D BEM formulation, is more accurate, however the computation effort required is somewhat higher.

In order to obtain a better discernment of the effects involved in the problem, the following sections are organized as follows: i) analysis of the dynamic behavior of the building including SSI effects; ii) detailed approach of the dynamic response of the building due to the train passage.

\section{Dynamic behaviour of the building.}

Fig. 7 shows the mode shapes of the building structure associated to the first twelve natural frequencies. The mode shapes herein presented were computed assuming full restriction of the degrees of freedom of the building that connect it to the ground, i.e., discarding the SSI effects.
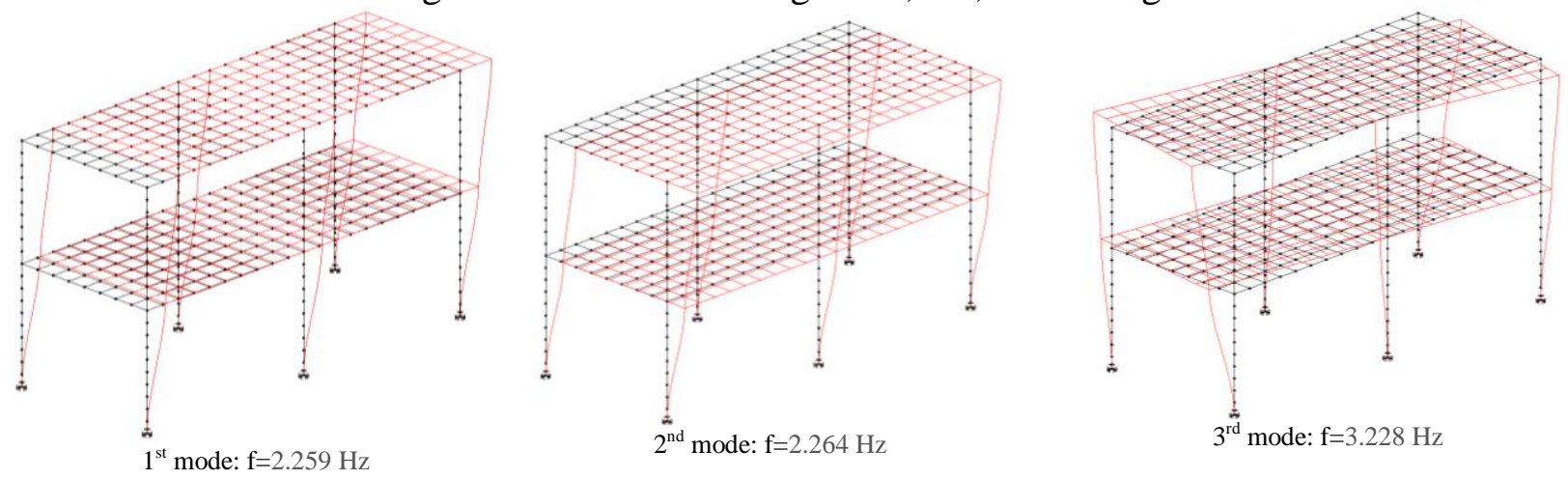

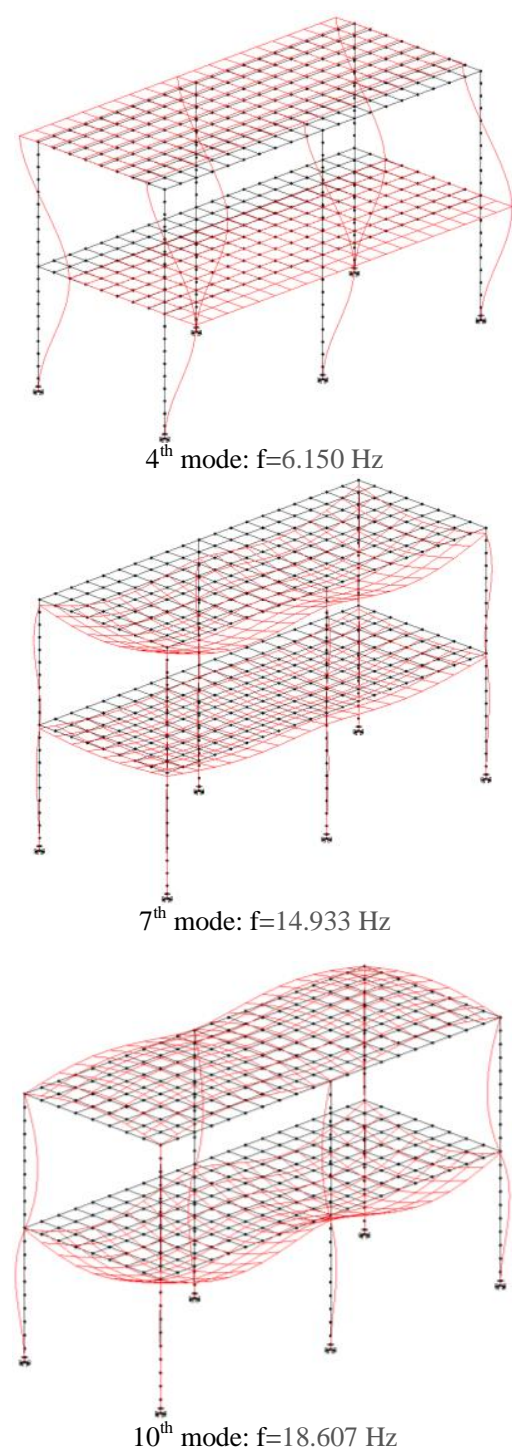

Fig. 7. Mode shapes of the building structure
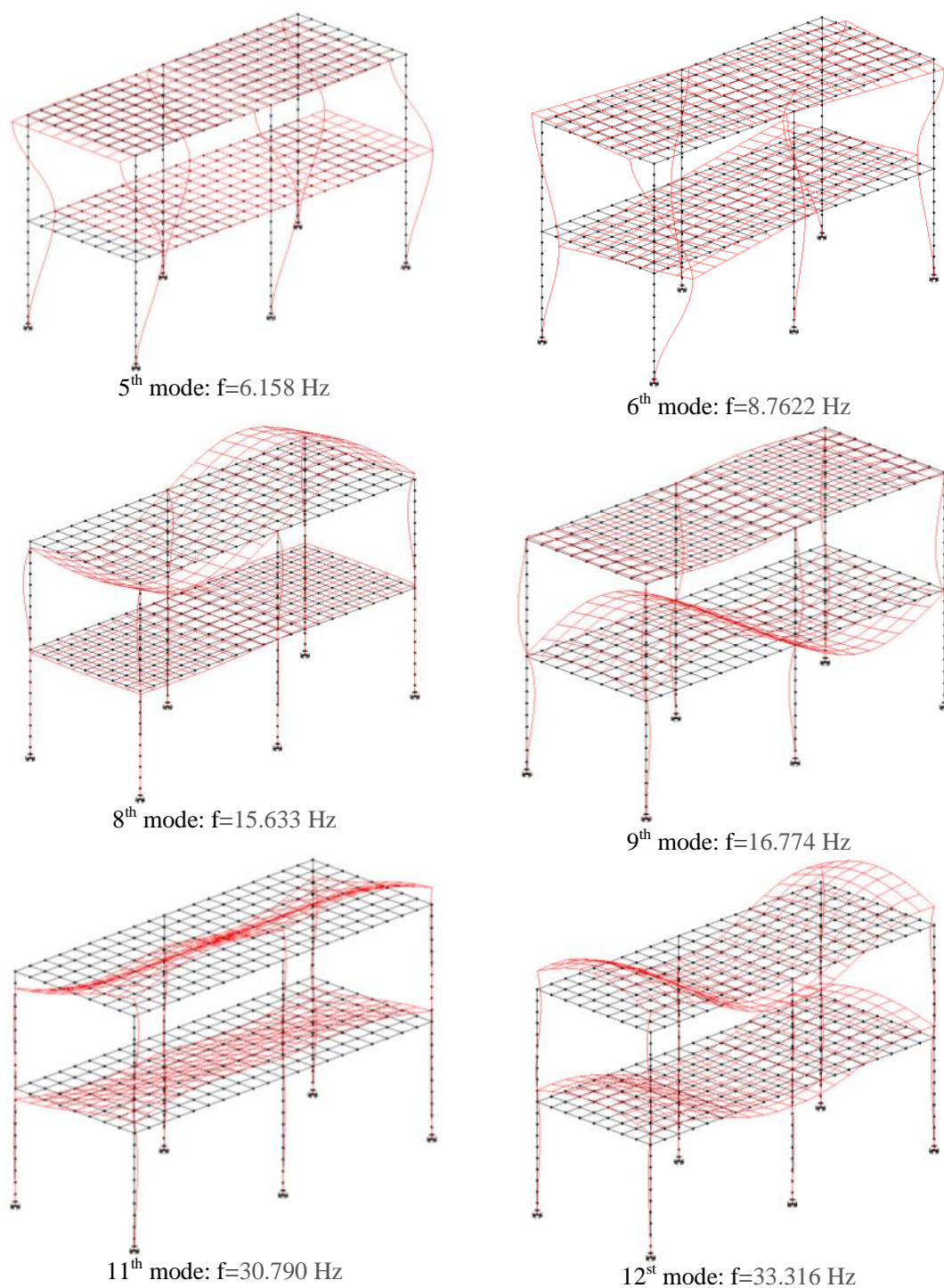
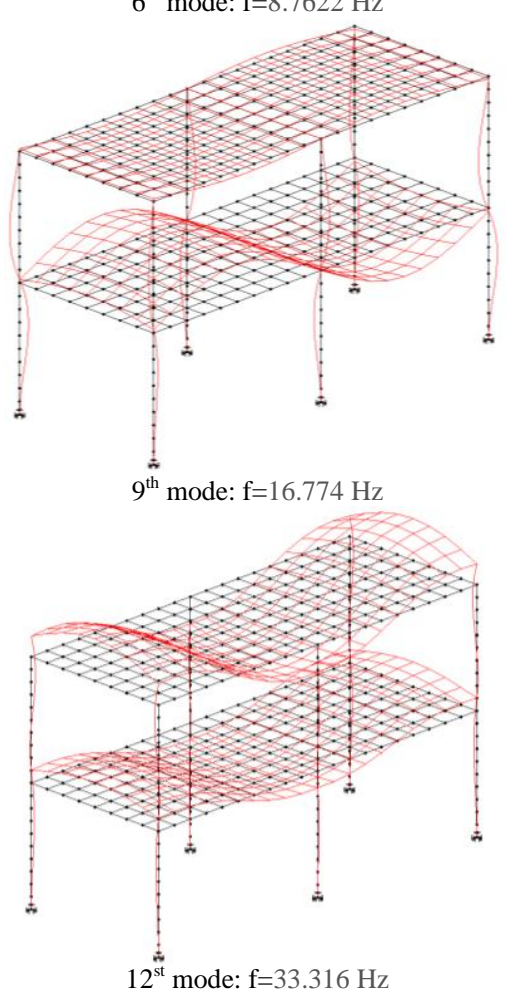

Observing Fig. 7, it is possible to conclude that the mode shapes related with natural frequencies up to $10 \mathrm{~Hz}$ comprise horizontal movement of the building slabs. On the other hand, the vertical movement of the slabs is mainly related to the natural frequencies that occur between $14 \mathrm{~Hz}$ and 20 $\mathrm{Hz}$, while the natural frequencies above $30 \mathrm{~Hz}$ are related with local mode shapes that also imply bending of the slabs and axial deformation of the columns.

Since the ground is not infinitely stiff, the SSI effect will influence the dynamic behaviour of the building. This influence is seen in the shift of the natural frequencies towards lower values, due to the increase of flexibility of the system, and also in the attenuation of the response amplitude due to the radiation of energy of the footing towards the ground. These effects are clearly observed in Fig. 8, where the FRF (Frequency Response Function) of the vertical displacement of point H (see Fig. 4) caused by a vertical unitary displacement applied at all footings of the building are depicted. In order to better discern the influence of the building-ground coupling, a null value was assumed for the damping of the building structure at Fig. 8a. 


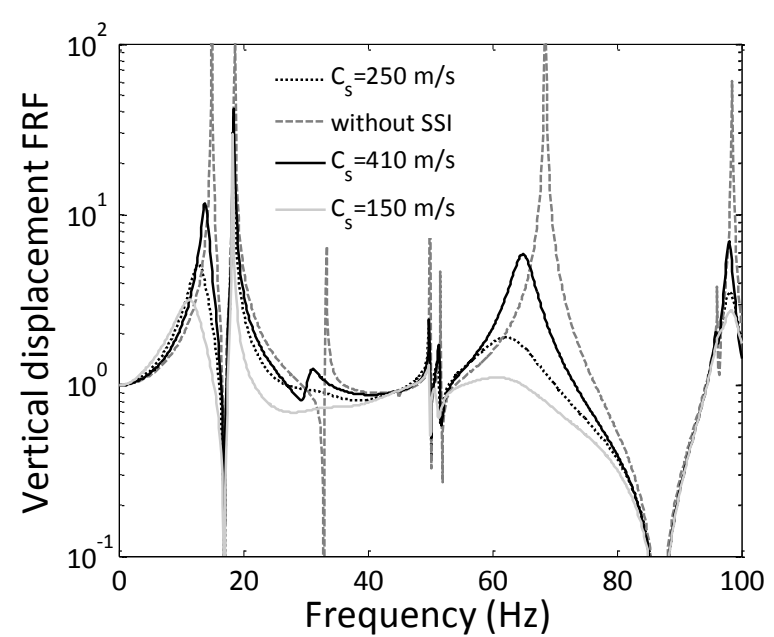

a

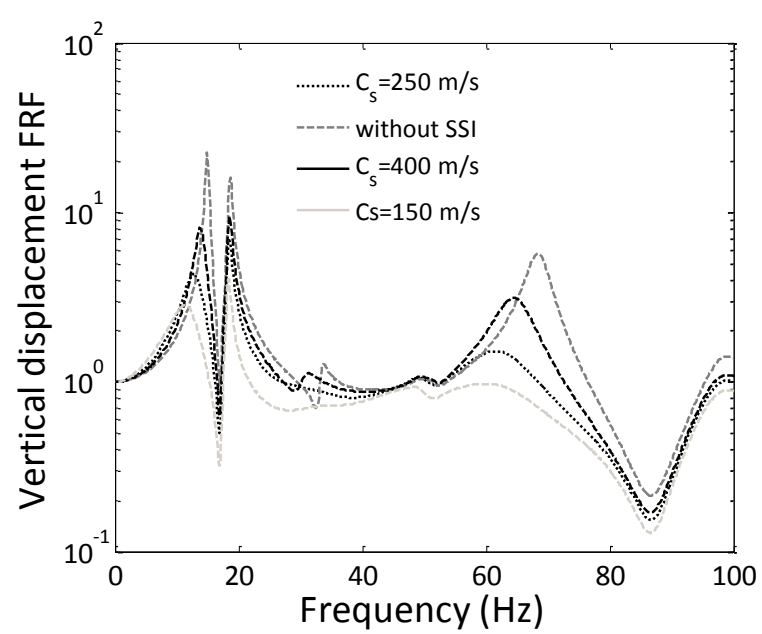

b

Fig. 8. FRF of the vertical displacement of point $\mathrm{H}$ caused by an unitary harmonic vertical displacement applied at the footings structure: a) undamped scenario; b) damped scenario.

As expected, the soil-structure interaction (SSI) has a huge influence on the dynamic behaviour of the building. This influence becomes more pronounced as the ground becomes softer. However, even for the stiffer scenario, it is possible to see a slight shift of the natural frequencies of the system associated with mode shapes where the vertical movement of the footings can be involved.

\section{The dynamic response of the building due to traffic induced vibrations}

In what the vertical dynamic response of the slabs of the building is concerned, it is possible to see a clear influence of soil stiffness in the results depicted in Fig. 9.

A first analysis of the results allows concluding that the peak vertical velocity increases as soil stiffness increases. Moreover, damping effect induced by the SSI is quite evident. For the stiffer scenario, it is possible to see a tail of free vibration of the building after the passage of the train, which is not so perceptible for the softer scenario.

Generally, the major concern when dealing with vibrations in buildings due to traffic has to do with the vertical component of the response. However, the properties of the soil also affect the horizontal components, as shown in the one-third octave spectra of the horizontal velocity (y-direction) depicted in Fig. 10. As can be seen, the frequency content of the response is concentrated in a narrow low frequency band, according to the natural frequencies of the building with the 2nd and 4th mode shapes. For the higher frequency range, the structure of the building acts as a "filter" of the incident wave field. However, it is notorious that the velocity increases with the decrease of the soil stiffness, since for this frequency range the system response is only affected by the quasi-static stiffness of the soil. 

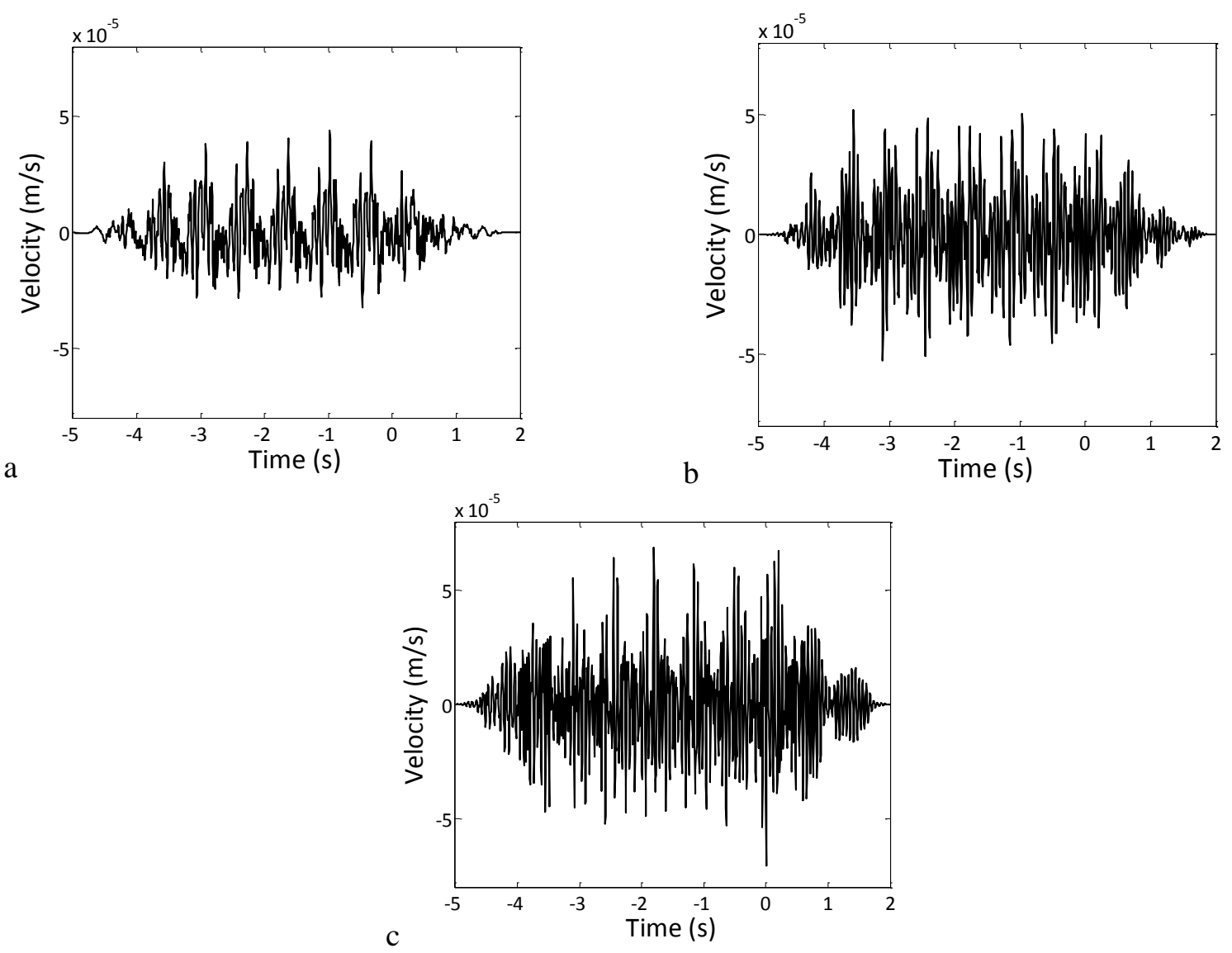

Fig. 9. Time record of the vertical velocity of point $\mathrm{H}$ : a) $\mathrm{Cs}=150 \mathrm{~m} / \mathrm{s} ;$ b) $\mathrm{Cs}=250 \mathrm{~m} / \mathrm{s} ; \mathrm{c}$ ) $\mathrm{Cs}=410 \mathrm{~m} / \mathrm{s}$.

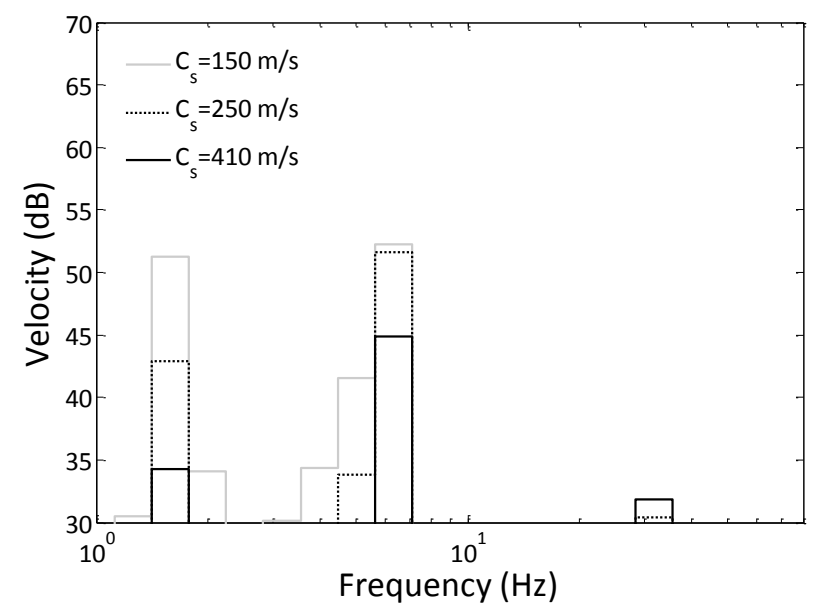

Fig. 10. One-third octave spectra of the horizontal velocity (y direction) of point $\mathrm{H}$ for different ground properties.

\section{The relevance of the SSI analysis and alternative approaches}

The results presented in the last section were computed assuming a detailed 3D FEM-BEM analysis of the building-ground system. However, alternative approaches, preferably more simple, can also be considered. The simplest way is neglecting the contribution of the ground on the dynamic behaviour of the building, i.e., assuming that the stiffness of the ground is so high that its contribution is not relevant. Taking into account the FRF functions presented before it seems that this option is only acceptable when considering very stiff grounds. However, between that and the detailed 
modelling of the ground impedance by a 3D BEM formulation, the reasonability of lumpedparameter models should be checked in more detail.

Fig. 11 compares the vertical velocity time history of point $\mathrm{H}$, computed by the three distinct methods for the softest and stiffest scenarios under analysis.
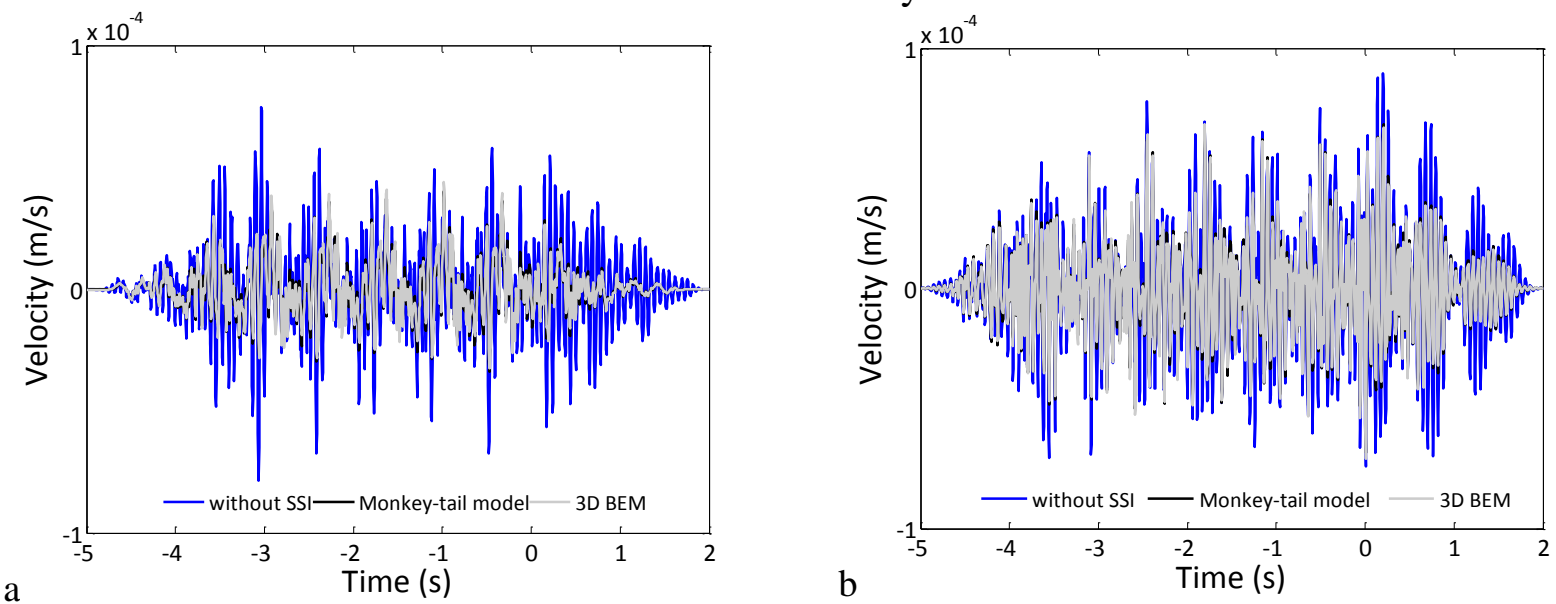

Fig. 11. The influence of SSI on the time record of the vertical velocity of point $\mathrm{H}$ : a) $\mathrm{Cs}=150$ $\mathrm{m} / \mathrm{s} ; \mathrm{b}) \mathrm{Cs}=410 \mathrm{~m} / \mathrm{s}$.

The results shown here point out two main remarks: i) the consideration of SSI effects is mandatory for an accurate assessment of vibrations inside of buildings due to railway traffic in tunnels; ii) in the present case, the results obtained using the monkey-tail model on the computation of the ground stiffness cope very well with the solution obtained by the 3D FEM approach. The first remark is particularly evident on Fig. 11a, where a strong overestimation of the peak values is achieved when SSI effects are discarded. These remarks gain robustness when analyzing the homologous results on the frequency domain, which can be seen in Fig. 12.
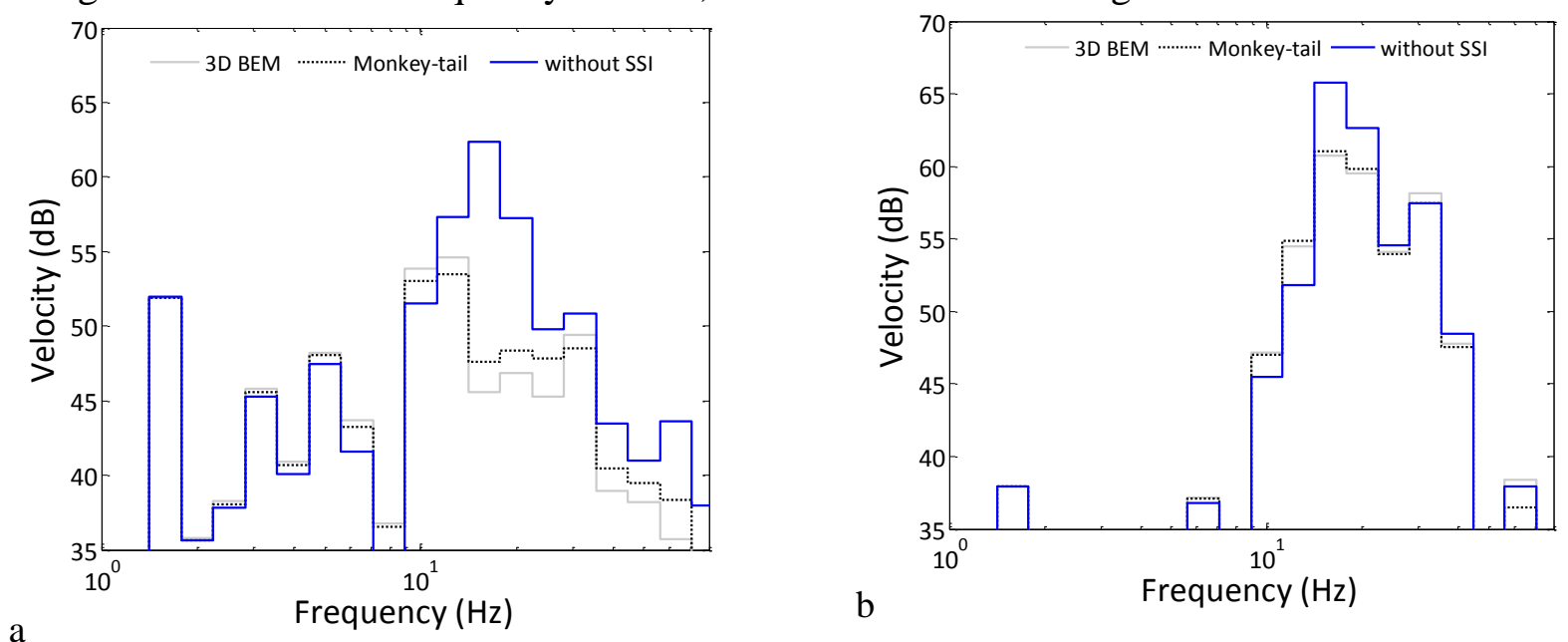

Fig. 12. The influence of SSI on the frequency content of the vertical velocity of point $\mathrm{H}$ : a) $\mathrm{Cs}=150$ $\mathrm{m} / \mathrm{s}$; b) $\mathrm{Cs}=410 \mathrm{~m} / \mathrm{s}$.

As can be observed, for the softer scenario, the SSI effects negligence can lead to the overestimation of the response up to $15 \mathrm{~dB}$ in the frequency range around $20 \mathrm{~Hz}$. This overestimation is minimized for $5 \mathrm{~dB}$ when the stiffer scenario is assumed. Despite the differences in the results obtained by the lumped-parameter model when compared with the 3D BEM, a general good agreement is obtained, even when ground stiffness is quite low, which highlights the potentialities of the model. 


\section{Conclusions}

A comprehensive numerical model was used to investigate of the influence of the soil stiffness on the vibrations induced by railway traffic in tunnels. The proposed model includes the simulation of the main aspects of the problem, i.e., the generation of vibrations, the propagation trough the ground and the reception of vibrations inside buildings surrounding the railway infrastructure. Due to the complexity of the problem, a sub-structuring approach was followed, using distinct numerical methods for the simulation of each part of the domain.

Concerning the parametric study developed about the influence of soil stiffness on the dynamic response of the system the following key conclusions were obtained:

i) The dynamic response of the track, as well as of the train, is not particularly affected by soil stiffness. This remark should be made carefully, since it is valid when resilient elements are included on the track. In these cases, almost all the flexibility of the track is given by these resilient elements and the soil stiffness influence is negligible.

ii) The influence of soil stiffness on the dynamic response of the building comprises two main parts: i) the influence of soil-stiffness on the "incident wave field"; ii) the influence of soil-stiffness on the dynamic behaviour of the building. The former aspect depends only on the propagation mechanism, and can be analyzed without the need of ground-structure interaction. As for the latter aspect, it was found that the influence of ground stiffness on the SSI mechanism is quite relevant, mainly when dealing with relatively soft ground.

iii) Since the lower frequency range dominates the response of the building on the horizontal directions, i.e., up to $8 \mathrm{~Hz}$, it is possible to establish the trend of the response to decrease with the increase of soil stiffness. Nevertheless, it should be noticed that this trend relies of the building structural characteristics, so the generalization of this conclusion should be made carefully.

iv) The reasonability of the usage of lumped-parameter models on this kind of problem was checked, and it was found that it constitutes an attractive alternative observing the compromise between accuracy and computational cost.

\section{References}

1. INCEJ, The Regional Environmental Vibrations. 2001: Tokyo.

2. Smith, M.G., et al., On the Influence of Freight Trains on Humans: A Laboratory Investigation of the Impact of Nocturnal Low Frequency Vibration and Noise on Sleep and Heart Rate. PLoS ONE, 2013. 8(2): p. e55829.

3. Hansen, H.M.M., High-speed ground transportation. Noise and vibration impact assessment 2005, Federal Railroad Administration.

4. Hussein, M. and H. Hunt, A numerical model for calculating vibration from a railway tunnel embedded in a full-space. Journal of Sound and Vibration, 2007. 305(3): p. 401-431.

5. Hussein, M. and H. Hunt, A computationally efficient software application for calculating vibration from underground railways. Journal of Physics Conference Series, 2009. 181(1): p. 1-6.

6. Clouteau, D., et al., Free field vibrations due to dynamic loading on a tunnel embedded in a stratified medium. Journal of Sound and Vibration, 2005. 283(1-2): p. 173-199.

7. Gupta, S., et al., A comparison of two numerical models for the prediction of vibrations from underground railway traffic. Soil Dynamics and Earthquake Engineering, 2007. 27(7): p. 608-624. 
8. Gupta, S., G. Degrande, and G. Lombaert, Experimental validation of a numerical model for subway induced vibrations. Journal of Sound and Vibration, 2009. 321: p. 786-812.

9. Hung, H. and Y. Yang, Analysis of ground vibrations due to underground trains by 2.5D finite/infinite element approach. Earthquake Engineering and Engineering Vibration, 2010. 9(3): p. 327-335.

10. Lai, C., et al., Prediction of railway-induced ground vibrations in tunnels Journal of Vibration and Acoustics, 2005. 127(5): p. 503-514.

11. Alves Costa, P., R. Calçada, and A. Cardoso, Influence of train dynamic modelling strategy on the prediction of track-ground vibrations induced by railway traffic. Proceedings of the Institution of Mechanical Engineers, Part F: Journal of Rail and Rapid Transit 2012. 226(4): p. 434-450.

12. Lombaert, G. and G. Degrande, Ground-borne vibration due to static and dynamic axle loads of InterCity and high-speed trains. Journal of Sound and Vibration, 2009. 319(3-5): p. 1036-1066.

13. Lopes, P., et al., Modeling of infinite structures by 2.5D FEM-PML. Application to the simulation of vibrations induced in tunnels, in Railways 2012. The First International Conference on Railway Technology: Research, Development and Maintenance, J. Pombo, Editor. 2012: Tenerife, Canarias.

14. Hussein, M., et al., The dynamic effect of a piled-foundation building on an incident vibration field from an underground railway tunnel, in 20th International Congress on Sound and Vibration 2013, ICSV 2013. 2013: Bangkok, Thailand. p. 1594-1601.

15. Lopes, P., et al., An efficient numerical model for the simulation of vibrations induced by railway traffic in tunnels, in ISEV 2013 - International Symposium on Environmental Vibrations. 2013: Shangai, China. p. 105-118.

16. Hussein, M., et al., The use of sub-modelling technique to calculate vibration in buildings from underground railways Proceedings of the Institution of Mechanical Engineers Part F: Journal of Rail and Rapid Transit, 2013: p. DOI: 10.1177/0954409713511449

17. Lopes, P., et al., Modelling of vibrations induced by traffic in tunnels: from the source to the receiver, in 11th International Conference on Vibration Problems, Z. Dimitrovová, Editor. 2013: Lisbon. p. 1-10.

18. Gupta, S., et al., Influence of tunnel and soil parameters on vibrations from underground railways. Journal of Sound and Vibration, 2009. 327: p. 70-91.

19. Lopes, P., et al., Numerical modelling of vibrations induced by railway traffic in tunnels: from the source to the nearby buildings. Soil Dynamics and Earthquake Engineering, 2014. 61-62: p. 269-285.

20. Lopes, P., et al., Numerical Modeling of Vibrations Induced in Tunnels: A 2.5D FEM-PML Approach, in Traffic Induced Environmental Vibrations and Controls: Theory and Application, H. Xia and R. Calçada, Editors. 2013, Nova. p. 133-166.

21. Lopes, P., et al., Influence of soil stiffness on vibrations inside buildings due to railway traffic: numerical study. Computers \& Geotechnics, 2014. 61: p. 277-291.

22. Yang, Y., S. Kuo, and H. Hung, Frequency independent infinite elements for analyzing semi-infinite problems. International Journal for Numerical Methods in Engineering, 1996. 39: p. 3553-3569.

23. Alves Costa, P., et al., A 2.5D finite element model for simulation of unbounded domains under dynamic loading, in 7th European Conference on Numerical Methods in Geotechnical Engineering, T. Benz and S. Nordal, Editors. 2010: Trondheim. p. 782-790. 